\title{
Discovery of $2^{\prime}-\alpha$-C-Methyl-2'- $\beta$-C-fluorouridine Phosphoramidate Prodrugs as Inhibitors of Hepatitis C Virus
}

\author{
Debin Zeng, Rui Zhang, Quandeng Nie, Lin Cao, Luqing Shang,* and Zheng Yin*
}

State Key Laboratory of Elemento-Organic Chemistry, College of Pharmacy and Tianjin Key Laboratory of Molecular Drug Research, Nankai University, Haihe Education Park, 38 Tongyan Road, Tianjin 300353, PR China

\section{Supporting Information}

ABSTRACT: $2^{\prime}-\alpha$-C-Methyl-2'- $\beta$-C-fluorouridine and its phosphoramidate prodrugs were synthesized and evaluated for their inhibitory activity against HCV. The structureactivity relationship analysis of the phosphoramidate moiety found that $17 \mathrm{~m}, 17 \mathrm{q}$, and $17 \mathrm{r}$ exhibit potent activities against $\mathrm{HCV}$, with $\mathrm{EC}_{50}$ values of $1.82 \pm 0.19,0.88 \pm 0.12$, and $2.24 \pm$ $0.22 \mu \mathrm{M}$, respectively. The docking study revealed that the recognition of the $2^{\prime}-\beta$-F by $\operatorname{Arg} 158,3^{\prime}-\mathrm{OH}$ by $\mathrm{N} 291$, and the Watson-Crick pairing with the template allowed $\mathbf{2 3}$ to form the in-line conformation necessary for its incorporation into the viral RNA chain.

KEYWORDS: hepatitis C virus, phosphoramidate prodrugs, docking, inhibitor, Hint 1

$\mathrm{H}$ epatitis C virus (HCV) is a small, single-stranded positive-sense RNA virus that was explicitly identified in $1989 .{ }^{1}$ The $9.6 \mathrm{~kb}$ RNA genome shares similarities with the genomes of flaviviruses and pestiviruses. ${ }^{2} \mathrm{HCV}$ infection is a global health problem that impacts approximately 180 million individuals, of which approximately 150 million people may proceed to develop chronic liver disease. A significant percentage of patients may ultimately progress to liver cirrhosis and eventually develop hepatocellular carcinoma. ${ }^{3} \mathrm{HCV}$ infection is also the primary reason for liver transplants among adults. The therapy for HCV infection has long been regular injections of pegylated $\alpha$-interferon with the daily oral administration of ribavirin (RBV). ${ }^{4}$ This standard of care (SOC) functions by enhancing the host immune system rather than acting directly on the virus. However, HCV patients undergoing this therapy may also suffer significant adverse effects, including fatigue, hemolytic anemia, depression, and flulike symptoms, which are poorly tolerated. In 2011, boceprevir and telaprevir, as HCV protease inhibitors, became available to treat $\mathrm{HCV}$ infection with genotype 1 in combination with ribavirin and pegylated interferon. ${ }^{5}$ In 2013, two new directacting antivirals (DAAs), simeprevir and sofosbuvir, were approved by the FDA, which significantly enhanced the available armory. ${ }^{6}$ However, the high cost for a course of treatment with sofosbuvir creates a considerable economic burden for patients. ${ }^{7}$ Hence, the search for novel DAAs that are safe and effective remains a necessary endeavor.

The HCV NS5B RNA-dependent RNA polymerase is a key enzyme in the replication of the virus. Therefore, it has become an attractive target for the development of small molecule inhibitors of viral replication. Nucleoside and nucleotide inhibitors of HCV (NIs) are a class of DAAs that show broad activity across HCV genotypes and a high barrier to the emergence of viral resistance. ${ }^{8}$ Structural modifications have been made to both the base and ribose sugar portions of a ribonucleoside to develop potent and selective anti-HCV inhibitors. ${ }^{9}$ Structural modifications of the ribose sugar portion focused primarily on the $1^{\prime}$-, $2^{\prime}$-, and $4^{\prime}$-positions. Structural modifications of the $2^{\prime}$-position mainly consisted of introducing an alkyl or including a methyl at the $\beta$-position and the substitution of $2^{\prime}-\mathrm{OH}$, for instance, NM107, $\mathrm{EC}_{50}=1.23 \mu \mathrm{M}$, PSI-6310, $\mathrm{EC}_{50}=4.5 \mu \mathrm{M}$, PSI-7977 (sofosbuvir), $\mathrm{EC}_{90}=0.42$ $\mu \mathrm{M}$ (Figure 1). ${ }^{10-12}$ Additionally, some NIs containing $2^{\prime}$ -



Figure 1. Nucleoside/nucleotide inhibitors of HCV.

spirocycloalkyl or $2^{\prime}$-spirocyclic ether groups showed anti-HCV activities. 2'-Deoxy-2'-spirocyclopropylcytidine $\left(1, \mathrm{EC}_{50}=7.3\right.$ $\mu \mathrm{M}$, Figure 1) was discovered as a new member of the class of $2^{\prime}$-modified nucleoside derivatives and showed potent anti$\mathrm{HCV}$ activity. ${ }^{13}$ A $2^{\prime}$-spiroetheruridine analogue $\left(2, \mathrm{EC}_{50}=\right.$

Received: July 11, 2016

Accepted: October 19, 2016

Published: October 19, 2016 
$14.9 \mu \mathrm{M}$, Figure 1) and its phosphoramidate prodrug (3, $\mathrm{EC}_{50}$ $=20.6 \mu \mathrm{M}$, Figure 1) exhibited medium activity against HCV. ${ }^{14}$ This may suggest that the $2^{\prime}-\alpha$-C-alkyl in nucleosides/ nucleotides might be tolerated and that the $2^{\prime}-\alpha-\mathrm{OH}$ or $2^{\prime}-\alpha$ $\mathrm{F}$ may not be essential for nucleosides/nucleotides to exhibit anti-HCV activity. Sofosbuvir, with the modification of $2^{\prime}-\beta$-C$\mathrm{CH}_{3}-2^{\prime}-\alpha-\mathrm{C}-\mathrm{F}$, shows potent activity against $\mathrm{HCV}$, with few adverse effects. Inspired by $2^{\prime}$-spiro nucleosides/nucleotides and sofosbuvir, $2^{\prime}-\alpha-\mathrm{C}-\mathrm{CH}_{3}-2^{\prime}-\beta-\mathrm{C}-\mathrm{F}$ uridine, and its phosphoramidate prodrugs were synthesized and evaluated to determine their inhibitory activity against $\mathrm{HCV}$ and investigate the impact of stereochemistry at the $2^{\prime}$-position on the anti-HCV activity.

The synthesis of intermediate $2^{\prime}-\alpha-\mathrm{C}-\mathrm{CH}_{3}-2^{\prime}-\beta$-C-F uridine 13 was illustrated in Scheme 1. D-Ribose was treated with

\section{Scheme 1. Preparation of $13^{a}$}
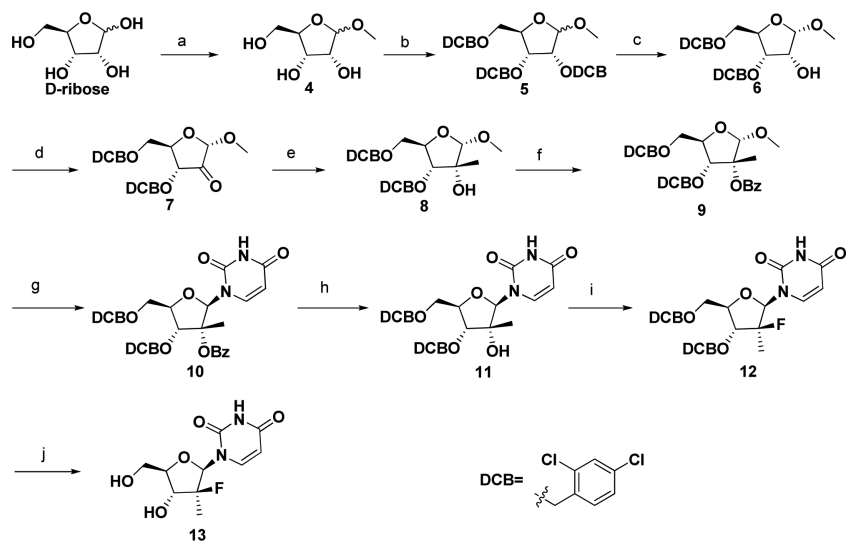

${ }^{a}$ Reagents and conditions: (a) $\mathrm{H}_{2} \mathrm{SO}_{4}, \mathrm{MeOH}$, r.t., $24 \mathrm{~h}$; (b) 2,4dichlorobenzyl chloride (DCBCl), NaH, DMF, $80{ }^{\circ} \mathrm{C}, 3 \mathrm{~h}, 60 \%$ for two steps; (c) $\mathrm{SnCl}_{4}, \mathrm{DCM}$, r.t., $3 \mathrm{~h}, 85 \%$; (d) 2,2,6,6tetramethylpiperidinooxy, trichloroisocyanuric acid, DCM, r.t., $3 \mathrm{~h}$, 90\%; (e) $\mathrm{CH}_{3} \mathrm{MgCl}$, THF, $-20{ }^{\circ} \mathrm{C}, 4 \mathrm{~h}, 85 \%$; (f) $\mathrm{BzCl}_{1} \mathrm{Et}_{3} \mathrm{~N}, \mathrm{DMAP}$, DCM, r.t., 2 h, $88 \%$; (g) uracil, N,O-bis(trimethylsilyl)acetamide, $\mathrm{SnCl}_{4}, \mathrm{CH}_{3} \mathrm{CN}, 50{ }^{\circ} \mathrm{C}, 4$ h, $88 \%$; (h) $\mathrm{LiOH}, \mathrm{CH}_{3} \mathrm{OH}$, r.t., 4 h, $95 \%$; (i) diethylaminosulfur trifluoride, DCM, $-40{ }^{\circ} \mathrm{C}, 2 \mathrm{~h}, 75 \%$; (j) $\mathrm{BCl}_{3}$, DCM, $-78{ }^{\circ} \mathrm{C}$ to $-30{ }^{\circ} \mathrm{C}, 2 \mathrm{~h}, 85 \%$.

concentrated sulfuric acid in methanol to obtain 1-O-methyl-Dribofuranose 4 . Then, the hydroxyl groups of $\mathbf{4}$ were protected by 2,4-dichlorobenzyl (DCB) groups to obtain $\mathbf{5}$, followed by the selective removal of the 2-O-DCB group in the presence of tin(IV) tetrachloride to obtain the alcohol 6. Ketone 7, obtained by the oxidation of the $2-\mathrm{OH}$ of alcohol 6 , was treated with methylmagnesium chloride to obtain 8 , followed by the protection of the $2-\mathrm{OH}$ with benzoyl chloride to obtain 9 . The treatment of the resulting intermediate with a silylated base and tin(IV) tetrachloride gave the uridine derivative 10. Then, the benzoyl group was removed to obtain alcohol 11, followed by the fluorination of the $2^{\prime}-\mathrm{OH}$ to obtain the $2^{\prime}-\alpha-\mathrm{C}-\mathrm{CH}_{3}-2^{\prime}-\beta-\mathrm{C}$ $\mathrm{F}$ uridine derivative 12. Finally, the DCB groups were removed to obtain the desired $2^{\prime}-\alpha-\mathrm{C}-\mathrm{CH}_{3}-2^{\prime}-\beta-\mathrm{C}-\mathrm{F}$ uridine 13.

The anti-HCV activity of $\mathbf{1 3}$ was evaluated by an in vitro $\mathrm{HCV}$ replicon cell system, ${ }^{15}$ and the results were expressed as $\mathrm{EC}_{50}$ values for antiviral activity and $\mathrm{CC}_{50}$ values for cytotoxicity. Uridine 13 presented medium anti-HCV activity, with an $\mathrm{EC}_{50}$ value of $14.65 \pm 1.21 \mu \mathrm{M}$ (Table 1 ). It was very interesting to find that the reverse stereochemistry of the $2^{\prime}$ carbon on the ribonucleoside compared to sofosbuvir was still active against $\mathrm{HCV}$.
Table 1. Structures of Phosphoramidate Prodrugs 17a-17i and in Vitro Anti-HCV Activities and Cytotoxicities

\begin{tabular}{|c|c|c|c|}
\hline Cmpd No. & $\mathrm{R}^{1}$ & $\mathrm{EC}_{50}{ }^{\mathrm{a}}(\mu \mathrm{M})$ & $\mathrm{CC}_{50}{ }^{\mathrm{a}}(\mu \mathrm{M})$ \\
\hline sofosbuvir & & $0.12 \pm 0.02$ & $>100$ \\
\hline 13 & - & $14.65 \pm 1.21$ & $>100$ \\
\hline $17 \mathbf{a}$ & $\xi$ & $>50$ & $>100$ \\
\hline $17 \mathbf{b}$ & & $>50$ & $>100$ \\
\hline $17 \mathrm{c}$ & & $>50$ & $>100$ \\
\hline $17 d$ & & $34.21 \pm 1.88$ & $>100$ \\
\hline $17 \mathrm{e}$ & & $>50$ & $>100$ \\
\hline $17 f$ & & $>50$ & $>100$ \\
\hline $17 \mathrm{~g}$ & & $>50$ & $>100$ \\
\hline $17 \mathrm{~h}$ & & $>50$ & $>100$ \\
\hline $17 \mathbf{i}$ & & $>50$ & $>100$ \\
\hline
\end{tabular}

${ }^{a}$ Measurements of in vitro activity and cytotoxicity were performed in triplicate and represent the mean \pm SD of at least three experiment sets.

Generally, nucleoside inhibitors of antiviral were believed to work as a chain terminator and needed to be converted intracellularly to their $5^{\prime}$-triphosphate derivatives to be active inhibitors of viral polymerases. So a series of phosphoramidate prodrugs based on $2^{\prime}-\alpha-\mathrm{C}-\mathrm{CH}_{3}-2^{\prime}-\beta-\mathrm{C}-\mathrm{F}$ uridine 13 were synthesized. As illustrated in Scheme 2, amino acid 14 was

Scheme 2. Preparation of Phosphoramidate Prodrugs ${ }^{a}$

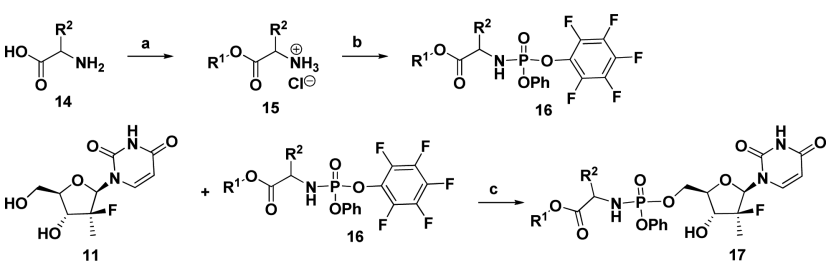

${ }^{a}$ Reagents and conditions: (a) $\mathrm{SOCl}_{2}$, alcohol, reflux, 2- $24 \mathrm{~h}, 75-$ 95\%; (b) phenyl dichlorophosphate, $\mathrm{Et}_{3} \mathrm{~N}$, 2,3,4,5,6-pentafluoro phenol, DCM $-78{ }^{\circ} \mathrm{C}$ to rt, $4 \mathrm{~h}, 60-85 \%$; (c) $t$-BuMgCl, THF, 0 ${ }^{\circ} \mathrm{C}, 12 \mathrm{~h}, 28-35 \%$.

reacted with an alcohol and thionyl chloride to obtain the amino acid ester hydrochloride 15, which reacted with phenyl dichlorophosphate and 2,3,4,5,6-pentafluoro phenol under basic conditions to obtain phosphoramidate 16. The reaction of intermediates 13 and 16 under basic conditions gave the desired phosphoramidate prodrugs 17 .

To explore the SAR of $\mathrm{R}^{1}$, $\mathrm{L}$-alanine was chosen as the amino acid, and various phosphoramidate prodrugs containing different ester groups were synthesized and evaluated (Table $1)$. With sofosbuvir $\left(\mathrm{EC}_{50}=0.12 \pm 0.02 \mu \mathrm{M}\right)$ as the control, the results showed that phosphoramidate prodrugs presented 
decreased activities compared to 13. The phosphoramidate prodrugs all exhibited weak activities $\left(\mathrm{EC}_{50}>50 \mu \mathrm{M}\right)$, except that $17 \mathrm{~d}$ showed medium activity, with an $\mathrm{EC}_{50}$ value of 34.21 $\pm 1.88 \mu \mathrm{M}$. Nevertheless, low toxicity $\left(\mathrm{CC}_{50}>100 \mu \mathrm{M}\right)$ was observed for all phosphoramidate prodrugs. The isopropyl group of $17 \mathrm{~d}$ as the fixed $\mathrm{R}^{1}$ moiety for phosphoramidate prodrugs was investigated in the following study.

To explore the structure-activity relationship (SAR) of $\mathrm{R}^{2}$, various phosphoramidate prodrugs containing different amino acids with different stereochemistries were synthesized and evaluated (Table 2). The results showed that most amino acid

Table 2. Structures of Phosphoramidate Prodrugs $17 \mathbf{j}-17 \mathrm{~s}$ and in Vitro Anti-HCV Activities and Cytotoxicities

\begin{tabular}{|c|c|c|c|}
\hline Cmpd No. & $\mathrm{R}^{2 a}$ & $\mathrm{EC}_{50}^{b}(\mu \mathrm{M})$ & $\mathrm{CC}_{50}{ }^{b}(\mu \mathrm{M})$ \\
\hline $17 j$ & $\mathrm{H}$ & $22.88 \pm 1.65$ & $>100$ \\
\hline $17 d$ & (L) $\mathrm{Me}$ & $34.21 \pm 1.70$ & $>100$ \\
\hline $17 \mathrm{k}$ & (D) $\mathrm{Me}$ & $34.34 \pm 1.85$ & $>100$ \\
\hline 171 & (L) $\mathrm{Me}_{2} \mathrm{CH}$ & $>50$ & $>100$ \\
\hline $17 \mathrm{~m}$ & (D) $\mathrm{Me}_{2} \mathrm{CH}$ & $1.82 \pm 0.19$ & $>100$ \\
\hline $17 n$ & (L) $\mathrm{PhCH}_{2}$ & $33.33 \pm 1.54$ & $>100$ \\
\hline $17 \mathrm{o}$ & (D) $\mathrm{PhCH}_{2}$ & $35.34 \pm 1.85$ & $>100$ \\
\hline $17 p$ & (L) indole-3- $\mathrm{CH}_{2}$ & $>50$ & $>100$ \\
\hline $17 q$ & (D) indole-3- $\mathrm{CH}_{2}$ & $0.88 \pm 0.12$ & $>100$ \\
\hline $17 \mathrm{r}$ & (L) $\mathrm{MeSCH}_{2} \mathrm{CH}_{2}$ & $2.24 \pm 0.22$ & $>100$ \\
\hline $17 \mathrm{~s}$ & (D) $\mathrm{MeSCH}_{2} \mathrm{CH}_{2}$ & $>50$ & $>100$ \\
\hline
\end{tabular}

$a_{\mathrm{L}}$ means from L-amino acid, $\mathrm{D}$ means from $\mathrm{D}$-amino acid.

${ }^{b}$ Measurements of in vitro activity were performed in triplicate and represent the mean $\pm \mathrm{SD}$ of at least three experiment sets.

side chains were accommodated. Phosphoramidate prodrugs with hydrogen, methyl, or benzyl groups at $R^{2}(17 j, 17 d, 17 k$, 17n, and 17o) exhibited comparable anti-HCV activities, with $\mathrm{EC}_{50}$ values of from $22.88 \pm 1.65$ to $35.34 \pm 1.85 \mu \mathrm{M}$, indicating that the chirality of the $\alpha$-carbon of the amino acid moieties has little effect on the anti-HCV activities of these phosphoramidate prodrugs. Interestingly, it was found that phosphoramidate prodrugs ( 171 and $\mathbf{1 7 p}$ ) containing an Lvaline or L-tryptophan moiety exhibited weak activities against $\mathrm{HCV}$ at the maximum testing concentration $(50 \mu \mathrm{M})$. However, phosphoramidate prodrugs $(\mathbf{1 7 n}$ and $17 \mathbf{q})$ with a $\mathrm{D}$-valine or D-tryptophan moiety displayed a significant improvement in activity, with $\mathrm{EC}_{50}$ values of $2.24 \pm 0.22$ and $0.88 \pm 0.12 \mu \mathrm{M}$, respectively. Surprisingly, phosphoramidate prodrugs containing a methionine moiety preferred an L-amino acid moiety $\left(\mathrm{EC}_{50}\right.$ values: $2.24 \pm 0.22 \mu \mathrm{M}$ for $17 \mathrm{r},>50 \mu \mathrm{M}$ for $\mathbf{1 7 s}$ ). It was reported that sofosbuvir and its analogues containing a modification of $2^{\prime}-\beta-\mathrm{C}-\mathrm{CH}_{3}-2^{\prime}-\alpha-\mathrm{C}-\mathrm{F}$ preferred L-amino acid moieties, ${ }^{16}$ suggesting that the conformation inversion of the $2^{\prime}$-chiral carbon might influence the preference for the chirality of the $\alpha$-carbon of the amino acid moieties. Favorable $\mathrm{CC}_{50}$ values $\left(\mathrm{CC}_{50}>100 \mu \mathrm{M}\right)$ were observed for all of the phosphoramidate prodrugs inhibitors in the in vitro cytotoxicity assay.

Phosphoramidate prodrugs cannot directly exhibit anti-HCV activities. According to the mechanism of sofosbuvir against $\mathrm{HCV},{ }^{12}$ phosphoramidate prodrugs 17 must be metabolized to the active triphosphate form by a metabolic pathway that may contain five steps (Figure 2A). The process from 17 to its corresponding $5^{\prime}$-monophosphate 21 involves two types of

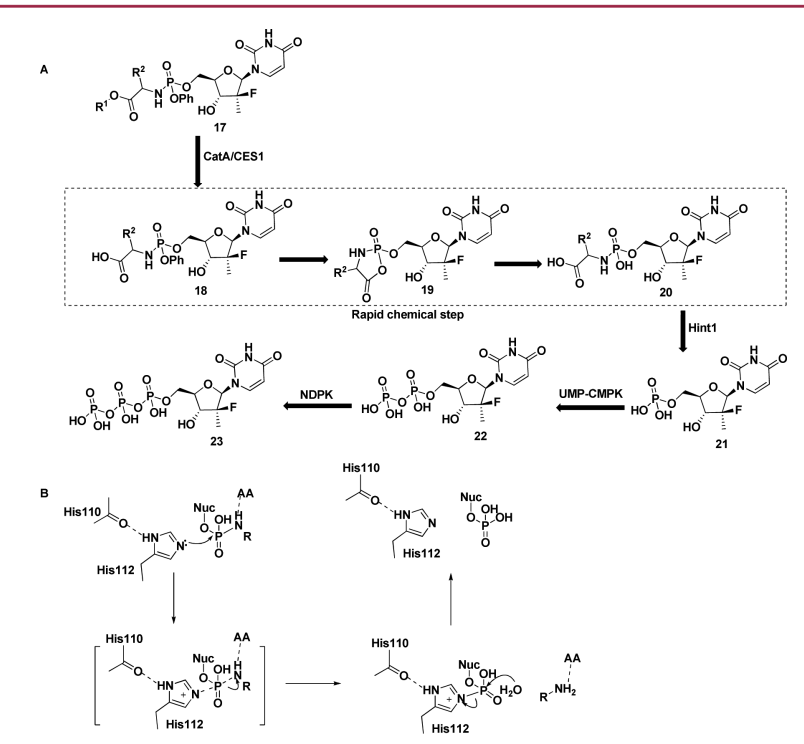

Figure 2. Formation of NTP. (A) Metabolic pathway for nucleoside phosphoramidates 17. (B) Catalytic mechanism for Hint 1.

enzyme, human cathepsin A (CatA)/carboxylesterase 1 (CES1) and histidine triad nucleotide-binding protein 1 (Hint 1$){ }^{12}$ Compounds $17 \mathbf{a}-17 \mathrm{c}$ and $17 \mathrm{e}-17 \mathbf{i}$ displayed weak activities against $\mathrm{HCV}$, probably because of the weak substrates for CatA/CES1. In 2007, Chou et al. ${ }^{17}$ reported that indolecontaining nucleoside phosphoramidates could be the substrates for Hint 1 , and the $k_{\text {cat }}$ value reached as high as approximately $2.5 \mathrm{~s}^{-1}$ for uridine phosphoramidates. Moreover, it was found that Hint 1 was sensitive to the configurations at the $\alpha$-carbon of the amino acid, preferring D- over L-tryptophan. This may be the reason why $\mathbf{1 7 q}$ was far more active against $\mathrm{HCV}$ than $17 \mathrm{p}$. To provide insight into the interactions between the phosphoramidate prodrugs and Hint 1, a docking study was performed using Autodock software.

In Hint 1 , His 110 and His 112 play important roles in the hydrolyzing the $\mathrm{P}-\mathrm{N}$ bond of the phosphoramidate prodrugs according to the histidine triad (HIT) protein family ${ }^{18}$ (Figure 2B). The carbonyl of His 110 formed a hydrogen bond with the imidazole of His112 to increase the basicity of the nitrogen atom, which attacked the phosphorus atom of the nucleoside phosphoramidates in the next step. The formation of a hydrogen bond between the $\mathrm{NH}$ of the phosphoramidates and Hint 1 was useful for the cleavage of the $\mathrm{P}-\mathrm{N}$ bond. In the docking study, the corresponding metabolites 20 of the phosphoramidate prodrugs were docked into Hint 1 . According to the docking models, $20 \mathrm{j}, 20 \mathrm{~d}, 20 \mathrm{k}, 20 \mathrm{n}$, and $20 \mathrm{o}$ interacted with Hint 1 in almost the same pattern (models not shown). The distance between the nitrogen atoms of His 112 and the phosphorus atom was between 3.8 and 4.1 A. Ser107 formed a hydrogen bond with the $\mathrm{NH}$ of the phosphoramidates. The interaction pattern of $20 \mathrm{~m}$ and Hint 1 is illustrated in Figure 3. The distance between the nitrogen atom of His 112 and phosphorus atom was 3.9 $\AA$. The side chain of Asn99 interacted with the $\mathrm{NH}$ of phosphoramidate ( $3.3 \AA$ ), promoting the formation of monophosphate 21. Moreover, the oxygen atom of the $\mathrm{P}-\mathrm{O}$ bonds formed hydrogen bonds with the side chain of His114 and the backbone of $\operatorname{Ser} 107$ (2.8 and $3.0 \AA$, respectively). Additionally, the backbone of Ile44 donated a 


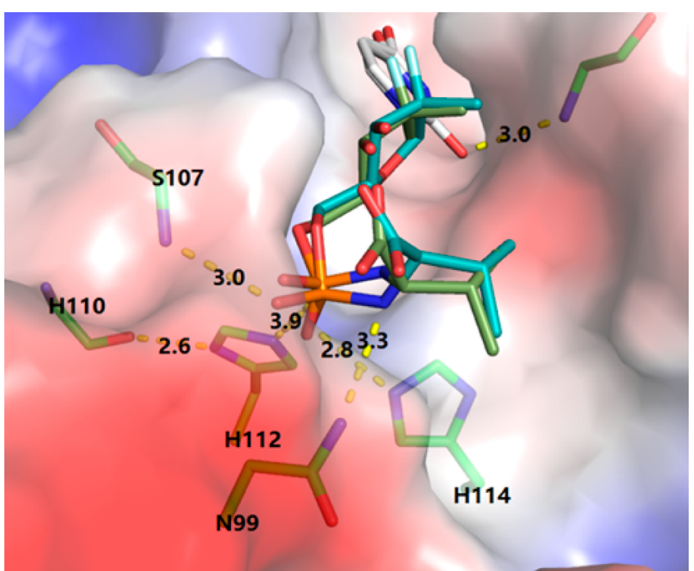

Figure 3. Docking models of 201 (smudge) and $20 \mathrm{~m}$ (cyan) bound to Hint 1 (PDB code: $1 \mathrm{KPF}$ ).

hydrogen bond to carbonyl of the base (3.0 ̊). COmpound 201 bonded to Hint 1 in almost the same pattern as $20 \mathrm{~m}$, except that no hydrogen bond interaction existed between the $\mathrm{NH}$ of 201 and Hint 1 because of the chirality of the $\alpha$ carbon (Figure 3), which might be the reason why 201 has a lower activity against HCV. The situations of $20 \mathrm{p}$ and $20 \mathrm{q}$ were similar to those of 201 and $20 \mathrm{~m}$. However, the chirality of the $\alpha$ carbon resulted in a great difference in the interactions between phosphoramidate prodrugs containing methionine and Hint 1 (Figure 4). The distance between the nitrogen atom of His 112

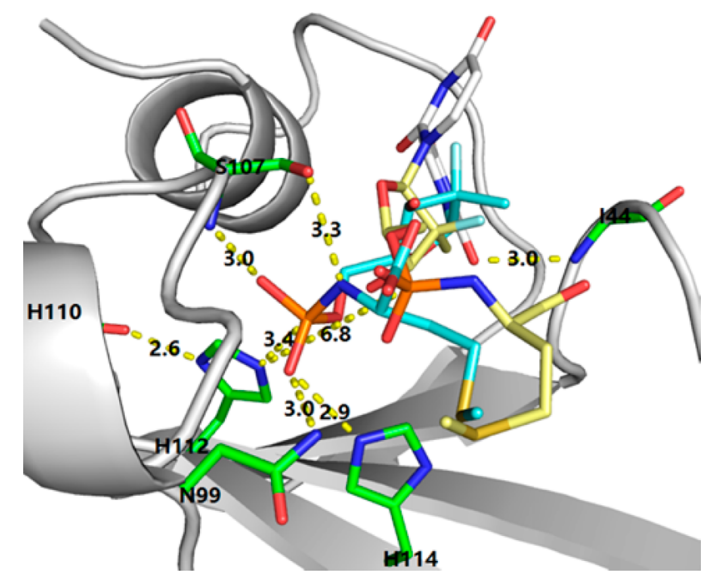

Figure 4. Docking models of 20r (cyan) and 20s (yellow) bound to Hint 1 (PDB code: $1 \mathrm{KPF}$ ).

and the phosphorus atom of 20r was $3.4 \AA$, and the $\mathrm{NH}$ of the L-methionine moiety interacted with the side chain of Ser107 (3.3 A). However, the distance between His112 and the phosphorus atom of 20s containing the D-methionine moiety was as great as $6.8 \AA$, which resulted in a loss of activity against HCV.

In 2015, Appleby reported the crystal structure for HCV 2a NS5B triple mutant $\Delta 8$ elongation state assemblies with sofosbuvir and proposed a model of $\mathrm{HCV}$ replication by $\mathrm{NS} 5 \mathrm{~B},{ }^{19}$ which provided us with insight into the interactions between the nucleotide and NS5B polymerase. Herein, triphosphate $2^{\prime}-\alpha$-C- $\mathrm{CH}_{3}-2^{\prime}-\beta$-C-F UTP 23 , the metabolite of phosphoramidate prodrugs 17 , was docked into NS5B polymerase using MOE software. Compound 23 and $2^{\prime}-\beta-\mathrm{C}$ Me- $2^{\prime}-\alpha$-C-F UDP (24) were overlaid to show the differences clearly (Figure 5A). It was reported that the recognition of the 2 '-F by N291 and the Watson-Crick pairing with the template
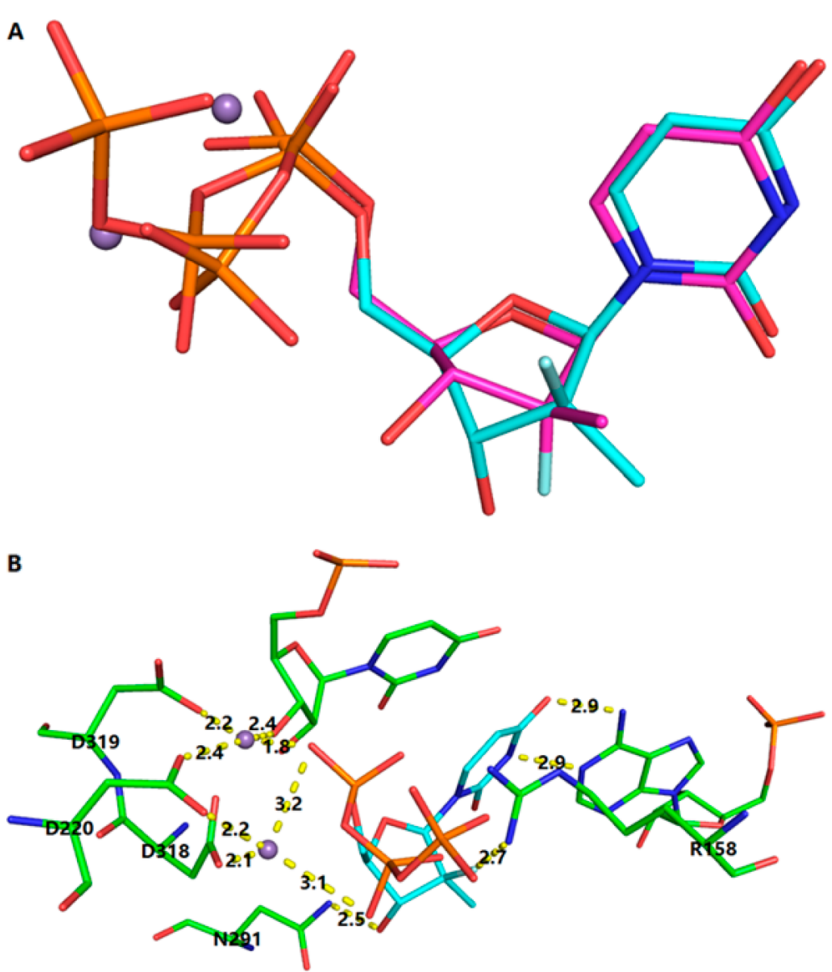

Figure 5. Docking models of $\mathbf{2 3}$ (cyan) bound to NS5B and cocrystal structure of 24 (magentas)/NS5B (PDB code: 4WTG). (A) Compounds 23 and $\mathbf{2 4}$ were overlaid to show the differences. (B) Recognition of 23 by NS5B.

allow 24 to form the in-line conformation necessary for incorporation into the growing chain. The docking model of 23 with NS5B revealed that the $3^{\prime}-\mathrm{OH}$ of 23 moved close to the side chain of Asn291 and formed a hydrogen bond (2.5 $\AA$ ), compared to 24 . Moreover, $2^{\prime}-\beta$-F was recognized by Arg 158 $(2.7 \AA)$. Along with the Watson-Crick pairing with the template, 23 could be identified by NS5B polymerase. The conserved catalytic residues Asp220, Asp 318, and Asp 319 coordinated the two catalytic $\mathrm{Mn}^{2+}$ ions, which in turn coordinated the $\alpha$ and $\beta$ phosphates of 23 (Figure 5B).

In summary, $2^{\prime}-\alpha-\mathrm{C}-\mathrm{CH}_{3}-2^{\prime}-\beta-\mathrm{C}-\mathrm{F}$ uridine 13 and a series of phosphoramidate prodrugs 17 were synthesized, and their antiHCV activities were evaluated. Phosphoramidates $17 \mathbf{m}, 17 \mathbf{q}$, and $17 \mathbf{r}$ exhibited potent activities against $\mathrm{HCV}$, with $\mathrm{EC}_{50}$ values of $1.82 \pm 0.19,0.88 \pm 0.12$, and $2.24 \pm 0.22 \mu \mathrm{M}$, respectively. The results revealed that conformation inversion of the $2^{\prime}$-chiral carbon might influence the preference for the chirality of the $\alpha$-carbon of the amino acid moieties compared to sofosbuvir. Favorable $\mathrm{CC}_{50}$ values $\left(\mathrm{CC}_{50}>100 \mu \mathrm{M}\right)$ were observed for all of the phosphoramidate inhibitors in the in vitro cytotoxicity assay. A docking study showed that the formation of a hydrogen bond between the $\mathrm{NH}$ of the phosphoramidates and Hint 1 had a significant impact on the cleavage of the $\mathrm{P}-\mathrm{N}$ bond, thus influencing the activities of the phosphoramidate prodrugs against HCV. Finally, the triphosphate 23 of phosphoramidate prodrugs 17 docked into NS5B polymerase. This revealed that the recognition of the $2^{\prime}-\beta-\mathrm{F}$ by Arg158 and $3^{\prime}-\mathrm{OH}$ by $\mathrm{N} 291$ and the Watson-Crick pairing 
with the template allowed $\mathbf{2 3}$ to form the in-line conformation necessary for incorporation into the viral RNA chain.

\section{ASSOCIATED CONTENT}

\section{S Supporting Information}

The Supporting Information is available free of charge on the ACS Publications website at DOI: 10.1021/acsmedchemlett.6b00270.

Full experimental details, in vitro antiviral activity and cytotoxicity assay (PDF)

\section{AUTHOR INFORMATION}

\section{Corresponding Authors}

*E-mail: zheng_yin@nankai.edu.cn.

*E-mail: shanglq@nankai.edu.cn.

\section{Author Contributions}

The manuscript was written through the contributions of all authors. All authors have given their approval to the final version of the manuscript.

\section{Funding}

This work was supported by the National Basic Research Program of China (973 program, Grant No. 2013CB911104, 2013CB911100), the National Natural Science Foundation of China (Grant No. 21202087, 31200586, 21572116), the Tianjin Science and Technology Program (Grant No. 13JCYBJC24300, 13JCQNJC13100), and the "111" Project of the Ministry of Education of China (Project No. B06005).

\section{Notes}

The authors declare no competing financial interest.

\section{REFERENCES}

(1) Choo, Q. L.; Kuo, G.; Weiner, A. J.; Overby, L. R.; Bradley, D. W.; Houghton, M. Isolation of a cDNA clone derived from a bloodborne non-A, non-B viral hepatitis genome. Science 1989, 244, 359362.

(2) Bartenschlager, R. Candidate targets for hepatitis C virus-specific antiviral therapy. Intervirology 1997, 40, 378-393.

(3) Lavanchy, D. The global burden of hepatitis C. Liver Int. 2009, 29, 74-81.

(4) Sofia, M. J. Nucleotide prodrugs for HCV therapy. Antiviral Chem. Chemother. 2011, 22, 23-49.

(5) Poordad, F.; Dieterich, D. Treating hepatitis C: current standard of care and emerging direct-acting antiviral agents. J. Viral Hepatitis 2012, 19, 449-464.

(6) Rehermann, B. Advances in hepatitis $\mathrm{C}$ research and treatment. Nat. Rev. Gastroenterol. Hepatol. 2016, 13, 70-71.

(7) Keating, G. M. Sofosbuvir: a review of its use in patients with chronic hepatitis C. Drugs 2014, 74, 1127-1146.

(8) Jensen, D. M.; Wedemeyer, H.; Herring, R. W.; Ferenci, P.; Ma, M. M.; Zeuzem, S.; Rodriguez-Torres, M.; Bzowej, N. H.; Pockros, P.; Vierling, J. M.; Ipe, D.; Hill, G. Z. High rates of early viral response, promising safety profile and lack of resistance-related breakthrough in HCV GT 1/4 patients treated with RG7128 plus PegIFN alfa-2a (40KD)/RBV: Planned Week 12 interim analysis from the Propel study. Hepatology 2010, 52, 360-361.

(9) Sofia, M. J.; Chang, W.; Furman, P. A.; Mosley, R. T.; Ross, B. S. Nucleoside, nucleotide, and non-nucleoside inhibitors of hepatitis $\mathrm{C}$ virus NS5B RNA-dependent RNA-polymerase. J. Med. Chem. 2012, 55, 2481-2531.

(10) Eldrup, A. B.; Allerson, C. R.; Bennett, C. F.; Bera, S.; Bhat, B.; Bhat, N.; Bosserman, M. R.; Brooks, J.; Burlein, C.; Carroll, S. S.; Cook, P. D.; Getty, K. L.; MacCoss, M.; McMasters, D. R.; Olsen, D. B.; Prakash, T. P.; Prhavc, M.; Song, Q.; Tomassini, J. E.; Xia, J. Structure-activity relationship of purine ribonucleosides for inhibition of hepatitis C virus RNA-dependent RNA polymerase. J. Med. Chem. 2004, 47, 2283-2295.

(11) Clark, J. L.; Hollecker, L.; Mason, J. C.; Stuyver, L. J.; Tharnish, P. M.; Lostia, S.; McBrayer, T. R.; Schinazi, R. F.; Watanabe, K. A.; Otto, M. J.; Furman, P. A.; Stec, W. J.; Patterson, S. E.; Pankiewiez, K. W. Design, synthesis, and antiviral activity of $2^{\prime}$-deoxy-2'-fluoro-2'-Cmethylcytidine, a potent inhibitor of hepatitis $\mathrm{C}$ virus replication. $J$. Med. Chem. 2005, 48, 5504-5508.

(12) Murakami, E.; Tolstykh, T.; Bao, H.; Niu, C.; Steuer, H. M. M.; Bao, D.; Chang, W.; Espiritu, C.; Bansal, S.; Lam, A. M.; Otto, M. J.; Sofia, M. J.; Furman, P. A. Mechanism of activation of PSI-7851 and its diastereoisomer PSI-7977. J. Biol. Chem. 2010, 285, 34337-34347.

(13) Jonckers, T. H. M.; Lin, T.-I.; Buyck, C.; Lachau-Durand, S.; Vandyck, K.; Van Hoof, S.; Vandekerckhove, L. A. M.; Hu, L.; Berke, J. M.; Vijgen, L.; Dillen, L. L. A.; Cummings, M. D.; de Kock, H.; Nilsson, M.; Sund, C.; Rydegård, C.; Samuelsson, B.; Rosenquist, Å.; Fanning, G.; Van Emelen, K.; Simmen, K.; Raboisson, P. 2'-Deoxy-2'spirocyclopropylcytidine revisited: a new and selective inhibitor of the hepatitis C virus NS5B polymerase. J. Med. Chem. 2010, 53, 81508160 .

(14) Du, J.; Chun, B.-K.; Mosley, R. T.; Bansal, S.; Bao, H.; Espiritu, C.; Lam, A. M.; Murakami, E.; Niu, C.; Micolochick Steuer, H. M.; Furman, P. A.; Sofia, M. J. Use of $2^{\prime}$-spirocyclic ethers in HCV nucleoside design. J. Med. Chem. 2013, 57, 1826-1835.

(15) Cui, H.-K.; Qing, J.; Guo, Y.; Wang, Y.-J.; Cui, L.-J.; He, T.-H.; Zhang, L.; Liu, L. Stapled peptide-based membrane fusion inhibitors of hepatitis C virus. Bioorg. Med. Chem. 2013, 21, 3547-3554.

(16) Sofia, M. J.; Bao, D.; Chang, W.; Du, J.; Nagarathnam, D.; Rachakonda, S.; Reddy, P. G.; Ross, B. S.; Wang, P.; Zhang, H.-R.; Bansal, S.; Espiritu, C.; Keilman, M.; Lam, A. M.; Steuer, H. M. M.; Niu, C.; Otto, M. J.; Furman, P. A. Discovery of a $\beta$-D- $2^{\prime}$-deoxy- $2^{\prime}-\alpha$ fluoro-2'- $\beta$-C-methyluridine nucleotide prodrug (PSI-7977) for the treatment of hepatitis C Virus. J. Med. Chem. 2010, 53, 7202-7218.

(17) Chou, T.-F.; Baraniak, J.; Kaczmarek, R.; Zhou, X.; Cheng, J.; Ghosh, B.; Wagner, C. R. Phosphoramidate pronucleotides: a comparison of the phosphoramidase substrate specificity of human and Escherichia coli histidine triad nucleotide binding proteins. Mol. Pharmaceutics 2007, 4, 208-217.

(18) Lima, C. D.; Klein, M. G.; Hendrickson, W. A. Structure-based analysis of catalysis and substrate definition in the HIT protein family. Science 1997, 278, 286-290.

(19) Appleby, T. C.; Perry, J. K.; Murakami, E.; Barauskas, O.; Feng, J.; Cho, A.; Fox, D., III; Wetmore, D. R.; McGrath, M. E.; Ray, A. S.; Sofia, M. J.; Swaminathan, S.; Edwards, T. E. Structural basis for RNA replication by the hepatitis C virus polymerase. Science 2015, 347, 771-775. 